\title{
Micropatterned Carbon-on-Quartz Electrode Chips for Photocurrent Generation from Thylakoid Membranes
}

Bunea, Ada-loana; Heiskanen, Arto R.; Pankratova, Galina; Tesei, Giulio; Lund, Mikael; Åkerlund, HansErik; Leech, Donal; Larsen, Niels Bent; Keller, Stephan Sylvest; Gorton, Lo

Total number of authors:

11

Published in:

Applied Energy Materials

Link to article, DOI:

10.1021/acsaem.8b00500

Publication date:

2018

Document Version

Peer reviewed version

Link back to DTU Orbit

Citation (APA):

Bunea, A-I., Heiskanen, A. R., Pankratova, G., Tesei, G., Lund, M., Åkerlund, H-E., Leech, D., Larsen, N. B., Keller, S. S., Gorton, L., \& Emnéus, J. (2018). Micropatterned Carbon-on-Quartz Electrode Chips for Photocurrent Generation from Thylakoid Membranes. Applied Energy Materials, 1(7), 3313-3322.

https://doi.org/10.1021/acsaem.8b00500

\section{General rights}

Copyright and moral rights for the publications made accessible in the public portal are retained by the authors and/or other copyright owners and it is a condition of accessing publications that users recognise and abide by the legal requirements associated with these rights.

- Users may download and print one copy of any publication from the public portal for the purpose of private study or research.

- You may not further distribute the material or use it for any profit-making activity or commercial gain

- You may freely distribute the URL identifying the publication in the public portal 
This document is confidential and is proprietary to the American Chemical Society and its authors. Do not copy or disclose without written permission. If you have received this item in error, notify the sender and delete all copies.

\section{Micropatterned Carbon-on-Quartz Electrode Chips for Photocurrent Generation from Thylakoid Membranes}

\begin{tabular}{|r|l|}
\hline Journal: & ACS Applied Energy Materials \\
\hline Manuscript ID & ae-2018-00500b.R1 \\
\hline Manuscript Type: & Article \\
\hline Date Submitted by the Author: & O7-May-2018 \\
\hline Complete List of Authors: & $\begin{array}{l}\text { Bunea, Ada-Ioana; Technical University of Denmark, Department of } \\
\text { Photonics Engineering } \\
\text { Heiskanen, Arto; Technical University of Denmark, Micro- and } \\
\text { Nanotechnology } \\
\text { Pankratova, Galina; Lund University, Biochemistry and Structural Biology } \\
\text { Tesei, Giulio; Lunds Universitet, Theoretical Chemistry } \\
\text { Lund, Mikael; Lund University, Department of Theoretical Chemistry } \\
\text { Akerlund, Hans-Erik; Lund University, Department of Biochemistry } \\
\text { Leech, Donal; National University of Ireland, Galway, Chemistry } \\
\text { Larsen, Niels; DTU-Nanotech, } \\
\text { Sylvest Keller, Stephan; DTU-Nanotech } \\
\text { Gorton, Lo; Lund University, Biochemistry } \\
\text { Emnéus, Jenny; Technical University of Denmark, Department of Micro and } \\
\text { Nanotechnology }\end{array}$ \\
\hline
\end{tabular}




\title{
Micropatterned Carbon-on-Quartz Electrode Chips
}

\section{for Photocurrent Generation from Thylakoid}

\section{Membranes}

\author{
Ada-Ioana Bunea ${ }^{a \dagger t}$, Arto Heiskanen ${ }^{a}$, Galina Pankratova ${ }^{b}$, Giulio Tesei ${ }^{c}$, Mikael Lund ${ }^{c}$, Hans- \\ Erik Akerlund ${ }^{b}$, Donal Leech ${ }^{d}$, Niels Bent Larsen ${ }^{a}$, Stephan Sylvest Keller ${ }^{a}$, Lo Gorton $^{b}$ and \\ Jenny Emnéus ${ }^{a \dagger}$
}

a. Department of Micro- and Nanotechnology, Technical University of Denmark, 2800 Kongens Lyngby, Denmark.

b. Department of Biochemistry and Structural Biology, Lund University, PO Box 124, 22100 Lund, Sweden.

c. Department of Theoretical Chemistry, Lund University, Chemical Center, PO Box 124, 22100 Lund, Sweden

d. School of Chemistry \& Ryan Institute, National University of Ireland, H91 CF50 Galway, Ireland

$\uparrow$ Corresponding authors. 


\begin{abstract}
KEYWORD: carbon, bioanode, thylakoid membranes, photosynthesis, pyrolysis, micropatterning.
\end{abstract}

\begin{abstract}
Harvesting the energy generated by photosynthetic organisms through light-dependent reactions is a significant step towards a sustainable future energy supply. Thylakoid membranes are the site of photosynthesis, and thus particularly suited for developing photo-bioelectrochemical cells. Novel electrode materials and geometries could potentially improve the efficiency of energy harvesting using thylakoid membranes. For commercial applications, electrodes with large surface areas are needed. Photolithographic patterning of a photoresist, followed by pyrolysis, is a flexible and fast approach for the fabrication of carbon electrodes with tailored properties. In this work, electrode chips consisting of patterned carbon supported on quartz were designed and fabricated. The patterned electrode area is $1 \mathrm{~cm}^{2}$, and the measurement chamber footprint is 0.5 $\mathrm{cm}^{2}$, one order of magnitude larger than previously-tested electrodes for thylakoid membrane immobilization. The use of a transparent substrate allows back-side illumination, protecting the bioelectrochemical system from the environment and vice versa. Two different mediators, monomeric $\left(\left[\mathrm{Ru}\left(\mathrm{NH}_{3}\right)_{6}\right]^{3+}\right)$ and polymeric $\left(\left[\mathrm{Os}(2,2 \text {-bipyridine })_{2} \text {-poly }(\mathrm{N} \text {-vinylimidazole })_{10} \mathrm{Cl}\right]^{+/ 2+}\right)$ are used for evaluating photocurrent generation from thylakoid membranes with different electrode geometries. Current densities up to $71 \mu \mathrm{A} \mathrm{cm} \mathrm{cm}^{-2}$ are measured upon illumination through the transparent electrode chip with solar simulated irradiance $\left(1000 \mathrm{~W} \mathrm{~m}^{-2}\right)$.
\end{abstract}

\title{
1. Introduction
}

Ever since the energy crisis of the 1970s, the energy demand has been increasing at both global and consumer level ${ }^{1-3}$. In the context of climate change, it is important not only to produce 
sufficient energy for our ever-growing needs, but also to move towards clean, renewable energy sources as a step towards a sustainable future ${ }^{4-6}$. In 2010 , renewable sources accounted for $16.6 \%$ of the energy consumed worldwide, and there is a projected increase to almost $50 \%$ by $2040^{6}$.

One of the main renewable energy sources is the Sun. Therefore, there is considerable focus on the development of methods for harvesting solar energy ${ }^{7-10}$. Solar energy is the primary energy source for organisms capable of photosynthesis, such as algae, green plants and cyanobacteria. For these organisms, photosynthesis takes place inside thylakoid membranes (TMs), which for algae and plants are found within chloroplasts ${ }^{11,12}$. The natural photosynthetic system is complex and involves numerous processes after photoexcitation. Two coupled protein complexes, photosystems I and II (PS I and PS II) are the key components in the light reactions of photosynthesis ${ }^{13-15}$. A variety of photosynthetic systems have been studied for harnessing sunlight in photo-bioelectrochemical cells (PBECs), e.g., isolated PS I and PS II ${ }^{14-16}, \mathrm{TMs}^{17-19}$, cyanobacteria ${ }^{20}$, Rhodobacter $\mathrm{sp}^{21,22}$, and algae ${ }^{23}$. However, in order to commercially explore PBECs, their efficiency needs to be substantially improved ${ }^{24}$ by increasing the rate of the extracellular electron transfer and the viability of these systems. There is an interest in developing mediator-less devices, but so far these show very low efficiency, with current densities below $2 \mu \mathrm{A} \mathrm{cm}^{-2} 18,25-27$. This is why most approaches use different soluble redox species and/or osmium redox polymers as mediators between photosynthetic components and electrodes $^{28,29}$. An improvement in the electrochemical interactions in such systems can be achieved at several levels, e.g., i) engineering of photosynthetic systems ${ }^{30}$; ii) improvement in the mediated electron transfer between the photosynthetic reactions centers and the electrodes; iii) development of new electrodes, which maximize the active surface area while minimizing 
diffusion distances, thus enhancing light distribution to the photosynthetic components and facilitating electron transfer.

In addition to improving the efficiency of PBECs, another important step towards commercial applications is fabricating the PBECs as closed systems in order to avoid possible undesired interactions between its components and the environment. One option for building a closed system, which still allows light to access the photosynthetic components, is the usage of a transparent bioanode.

Photovoltaic systems make use of transparent electrode materials as an integral part of the device architecture ${ }^{31}$ and transparent conducting oxides (TCOs) are the most commonly used materials because of their good conductivity and transparency. Several options are available, from well-known indium-based materials, such as ITO (indium tin oxide), to doped $\mathrm{ZnO}, \mathrm{TiO}_{2}$ and $\mathrm{SnO}_{2}$ materials ${ }^{31,32}$. Recently, fluorinated-tin oxide (FTO), was used as electrode material in a $\mathrm{PBEC}^{33}$. However, illumination was done from the top, without taking advantage of the transparency of FTO. An ITO biosupercapacitor was also recently reported ${ }^{25}$. Due to high costs and limited availability, researchers are interested in potential alternatives to TCOs ${ }^{34-37}$, with graphene, carbon nanotubes and metal nanowire electrodes showing most promise.

Carbon, with its different allotropes, is one of the most widely used electrode materials, especially for fuel cell applications ${ }^{38-40}$, because of its numerous advantages: abundance, low fabrication costs, wide potential window, relatively inert chemistry, biocompatibility and good electrocatalytic activity ${ }^{41}$. Photolithography can be used to deposit and pattern a polymeric photoresist onto a substrate of choice in a simple, scalable process. Moreover, photolithography potentially enables increasing the surface area by facilitating patterning of three-dimensional structures $^{42-44}$. By pyrolyzing the polymer precursor in inert atmosphere at temperatures above 
$900{ }^{\circ} \mathrm{C}$, glass-like carbon is obtained, while the pattern defined in the precursor is preserved ${ }^{45}$. Quartz is transparent in the UV-Vis domain, hard, durable and thermally resistant up to 1600 ${ }^{\circ} \mathrm{C}^{46}$. These properties identify it as an excellent substrate for developing transparent chips with patterned carbon electrodes on a large area.

Here we report the application of carbon electrode chips, fabricated through the pyrolysis of photoresist, for harvesting the energy generated by a photosynthetic system. Different carbon electrode patterns were defined on quartz substrates to investigate i) the trade-off between the transparent area available for photosynthesis and the opaque carbon electrode area required for photocurrent collection (open area fraction) and ii) the influence of the distance between the photosynthetic reaction centers (PRCs) and the carbon electrode surface on photocurrent generation. Additionally, the influence of the illumination power density on photocurrent collection was investigated. TMs were used as model light-harnessing systems, since they are easier to extract and purify than PS I and PS II, and at the same time more stable, because all the protein complexes retain their native environment. Photocurrent generation from TMs was tested with one soluble mediator, $\left[\mathrm{Ru}\left(\mathrm{NH}_{3}\right)_{6}\right]^{3+}$, and one redox polymer mediator, $\left[\mathrm{Os}\left(2,2^{\prime}\right.\right.$ bipyridine $)_{2}$-poly $\left.(\mathrm{N} \text {-vinylimidazole })_{10} \mathrm{Cl}\right]^{+/ 2+} 29$. Experimental data was analyzed through a theoretical diffusion model, which provides insight into the processes taking place in the bioelectrochemical system.

\section{Results and discussion}

\subsection{Measurement system and micropatterned electrode chips}

\subsubsection{Measurement system and redox reactions}

The fabricated electrode chips consist of carbon electrodes on a transparent carrier substrate. The quartz substrate is transparent in the visible range, but it is non-conductive ${ }^{46}$. The carbon 
electrodes are opaque, but good electrical conductors ${ }^{47,48}$. Since photocurrent generation requires light and photocurrent collection requires conductivity, there is a trade-off between the degree of exposed quartz and carbon areas of the chip. The measurement holder (Supporting information (SI) Figure S1) defines the electrode footprint in the center of the patterned electrode area and it ensures that i) light from the source can reach the sample in a reproducible manner and ii) the path that the electrons need to travel outside the patterned area is the same regardless of the design. The same holder was employed for all the experiments in this study.

A side-view schematic representation of the measurement system, using illumination from the backside of the electrode chips, is shown in Figure 1a. Light passes through the transparent carrier substrate and reaches the TMs in the areas with openings in the carbon layer. The TM layer is immobilized on the surface of the electrode chips with the aid of a dialysis membrane, which is held in place by an O-ring and the measurement holder. The reference electrode and the counter electrode are immersed in the electrolyte solution on the side of the measurement chamber, without being directly exposed to light.

A mediator, in its oxidized form, can be reduced by electrons generated in the water splitting photoreaction activated by the exposure of TMs to light. The reduced mediator can be reoxidized at the electrode surface, provided that the electrode is polarized at a suitable potential. Here, the soluble mediator, $\left[\mathrm{Ru}\left(\mathrm{NH}_{3}\right)_{6}\right]^{3+}$ is first reduced to $\left[\mathrm{Ru}\left(\mathrm{NH}_{3}\right)_{6}\right]^{2+}$ in contact with TMs exposed to light by the generated photoelectrons. $\left[\mathrm{Ru}\left(\mathrm{NH}_{3}\right)_{6}\right]^{2+}$ can then diffuse freely in the system. When it reaches the electrode surface, which is polarized at $0 \mathrm{~V}$ (vs. $\mathrm{Ag} \mid \mathrm{AgCl}_{\mathrm{sat}}$ ), $\left[\mathrm{Ru}\left(\mathrm{NH}_{3}\right)_{6}\right]^{2+}$ is re-oxidized to $\left[\mathrm{Ru}\left(\mathrm{NH}_{3}\right)_{6}\right]^{3+}$ and the corresponding photocurrent is recorded. Similarly, for the osmium redox polymer as mediator, $\mathrm{Os}^{3+}$ moieties are reduced to $\mathrm{Os}^{2+}$ by electrons generated by TMs when exposed to light. Charge is then transported in the redox 
polymer by $\sigma$ bonds and an electron hopping mechanism $^{49}$ to the electrode, which is polarized at $+0.22 \mathrm{~V}$ (vs. $\mathrm{Ag} \mid \mathrm{AgCl}_{\mathrm{sat}}$ ). At the electrode surface, the re-oxidation of $\mathrm{Os}^{2+}$ to $\mathrm{Os}^{3+}$ takes place, and the corresponding photocurrent is recorded. A schematic representation of the redox reactions and charge transport taking place in the measurement system is shown in Figure 1b. 

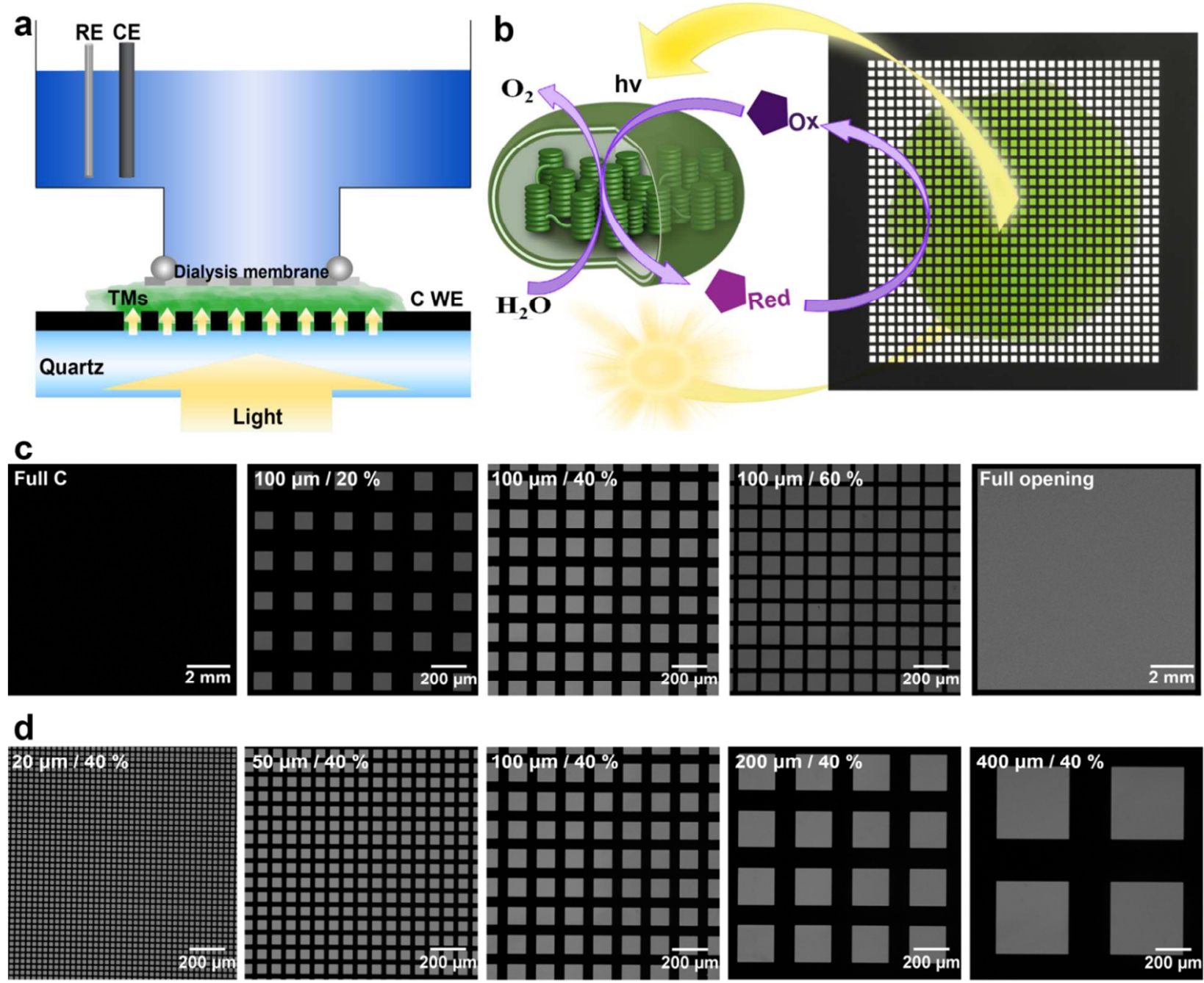

Figure 1: (a) Schematic representation of the measurement system - cross-sectional view: thylakoid membranes (TMs) immobilized on the surface of the patterned electrode area with the use of a dialysis membrane. The sample is illuminated from the backside and light reaches the TMs through the openings in the carbon layer, which represents the carbon working electrode (CWE). The reference electrode (RE) and counter electrode (CE) are placed on the side to avoid direct exposure to light; (b): Schematic of reactions taking place in the system - top view: light passes through the electrode chips and reaches the TMs, which then perform photolysis of water. Electrons generated in the process reduce a mediator present in the system, which is then transported and subsequently re-oxidized at the electrode surface; $(\mathrm{c}, \mathrm{d})$ : Microscopy images at 5x magnification of $100 \mu \mathrm{m}$ wide openings with different open area fractions (0-100\%) (c) and of openings of different widths $(20-400 \mu \mathrm{m})$ for a constant open area fraction of $40 \%(\mathrm{~d})$. The black areas show the carbon and the gray areas show the quartz substrate exposed by the openings.

The efficiency of the mediating system is expected to be dependent on three parameters: i) the thermodynamic driving force, which is related to the formal potential, $\mathrm{E}^{\circ}$, of the mediator; ii) the likelihood for the mediator to reach the reaction centers in the TMs and pick up the charge; and iii) the diffusion coefficient of the mediator in the system. The $\mathrm{E}^{\circ}$ of the $\mathrm{Os}^{3+} / \mathrm{Os}^{2+}$ redox 
couple in the Os polymer is higher $\left(+0.22 \mathrm{~V}\right.$ vs. $\left.\mathrm{Ag} \mid \mathrm{AgCl} \mathrm{sat}_{\mathrm{sat}}\right)$ than that of the $\left[\mathrm{Ru}\left(\mathrm{NH}_{3}\right)_{6}\right]^{3+} /\left[\mathrm{Ru}\left(\mathrm{NH}_{3}\right)_{6}\right]^{2+}$ redox couple $\left(-0.1 \mathrm{~V} \text { vs. } \mathrm{Ag} \mid \mathrm{AgCl}_{\mathrm{sat}}\right)^{50}$ and thus the Os polymer has a higher thermodynamic driving force to act as an efficient mediator. However, the monomeric $\left[\mathrm{Ru}\left(\mathrm{NH}_{3}\right)_{6}\right]^{3+}$ ions should have easier access to the reaction centers in the TMs. It is also expected that the diffusivity of the monomeric $\left[\mathrm{Ru}\left(\mathrm{NH}_{3}\right)_{6}\right]^{3+}$ ions within the system is higher than that of the $\mathrm{Os}^{3+} / \mathrm{Os}^{2+}$-redox moieties bound to the end of the side chains of the polymeric backbone. Furthermore, due to the strongly cationic nature of the Os redox polymer it is expected that there will be strong electrostatic interactions between the negatively charged TMs and the polymer. Thus, the Os redox polymer will act as both mediator and immobilization matrix for the TMs, which the monomeric $\left[\mathrm{Ru}\left(\mathrm{NH}_{3}\right)_{6}\right]^{3+} /\left[\mathrm{Ru}\left(\mathrm{NH}_{3}\right)_{6}\right]^{2+}$ ions will not be able to do.

\subsubsection{Micropatterned electrode chips}

Each electrode chip design is characterized by two parameters: i) the open area fraction, which is expressed as the percentage of the area that is not covered by carbon and therefore transparent to light; and ii) the width of the openings in the carbon layer (in $\mu \mathrm{m}$ ). The trade-off for photocurrent generation between the amount of light reaching the TMs and the electrode surface area was investigated using electrode chips with square openings with a width of $100 \mu \mathrm{m}$ and open area fractions between $0 \%$ and 100\% (Figure 1c). There are two particular cases: $0 \%$ open area fraction, denoted as "full C", and $100 \%$ open area fraction, denoted as "full opening". The influence of the distance between the photosynthetic sites and the electrode surface was evaluated by using electrode chips with a constant open area fraction of $40 \%$ and with square openings with widths between $20 \mu \mathrm{m}$ and $400 \mu \mathrm{m}$ (Figure 1d).

\subsection{Photocurrent generation using thylakoid membranes}


TMs were immobilized on the patterned electrode chips and tested for photocurrent generation using back-side illumination with an irradiance of $500 \mathrm{~W} \mathrm{~m}^{-2}$ with both the soluble mediator (Figure 2a and 2c) and the osmium redox polymer (Figure $\mathbf{2 b}$ and $\mathbf{2 d}$ ). Arrows in the figures indicate when the lamp was turned on and off. For all the experiments, no photocurrent was generated in the absence of light, i.e., when the lamp was off. When the lamp was turned on, the current increased instantly, after which it slowly declined while the sample was illuminated. This current decline was previously reported to be due to photo-induced damage of PS $\mathrm{II}^{29,51}$.

a

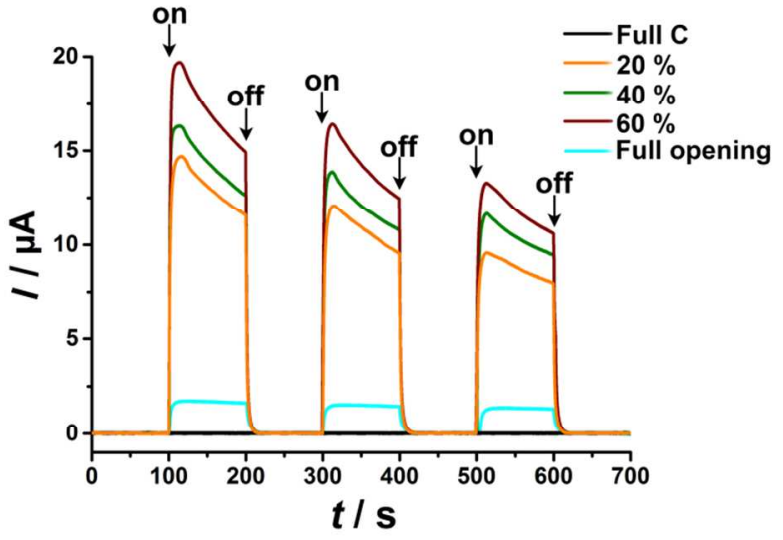

C

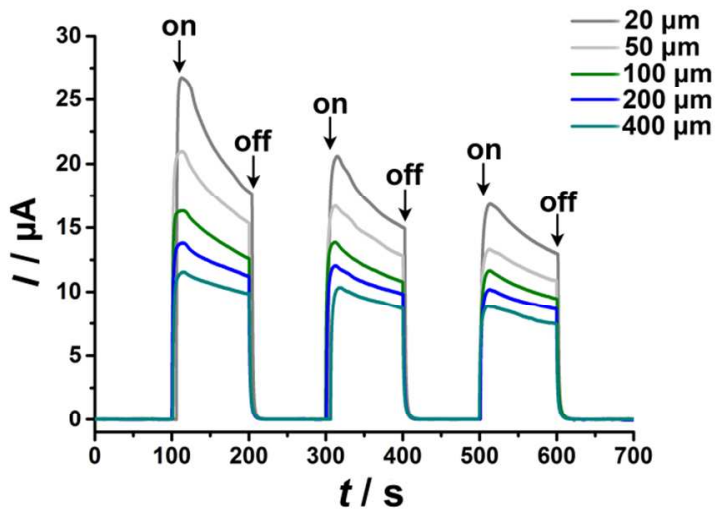

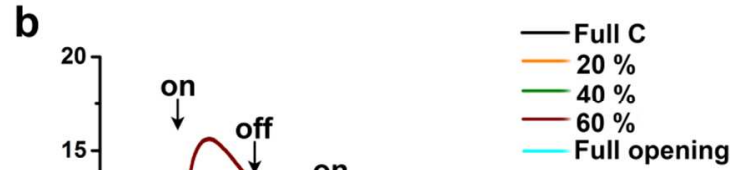
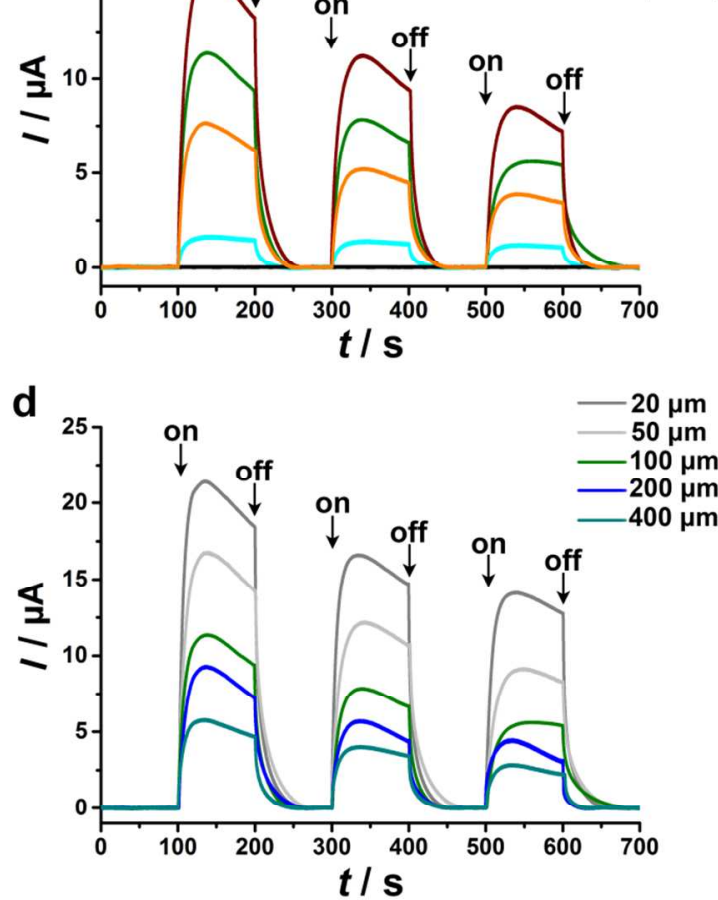

Figure 2: Current-time trace for photocurrent collection from TMs using different electrode chip patterns and mediators. (a,b): Constant opening width of $100 \mu \mathrm{m}$ and open area fractions between 0 and $100 \%$ (see also Figure 1c); (c, d): Constant open area fraction of $40 \%$ and varying opening widths between 20 and $400 \mu \mathrm{m}$ (see also Figure 1d). Measurement conditions: $1 \mathrm{mM}\left[\mathrm{Ru}\left(\mathrm{NH}_{3}\right)_{6}\right]^{3+}$ mediator in PBS at $\mathrm{E}=0 \mathrm{~V}$ vs. $\mathrm{Ag} \mid \mathrm{AgCl}_{\text {sat }}(\mathrm{a}, \mathrm{c})$ or osmium redox polymer mediator at $\mathrm{E}=+0.22 \mathrm{~V}$ vs. $\mathrm{Ag} \mid \mathrm{AgCl}_{\text {sat }}(\mathrm{b}, \mathrm{d})$.

\subsubsection{Influence of the open area fraction on photocurrent generation}




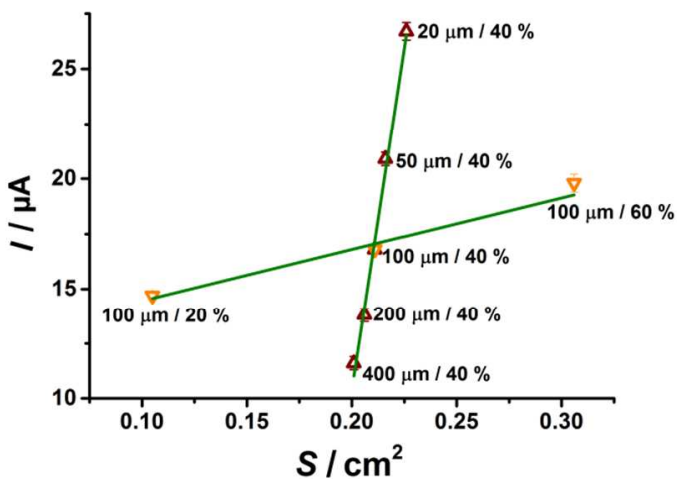

Figure 3: Maximum measured current plotted vs. the total surface area of the openings for photocurrent collection from TMs using different electrode chip patterns and $1 \mathrm{mM}\left[\mathrm{Ru}\left(\mathrm{NH}_{3}\right)_{6}\right]^{3+}$ in $\mathrm{PBS}$ as mediator. $\mathrm{E}=0 \mathrm{~V}$ vs. $\mathrm{Ag} \mid \mathrm{AgCl}_{\text {sat. }}$. The electrode footprint was $0.5 \mathrm{~cm}^{2}$ for all cases.

Since TMs need light to generate energy, an increase in photocurrent generation can be expected when the area exposed to light increases. This was verified for both mediators by data in Figure 2a, 2b, Figure 3 and Table 1S, showing how an increase in the open area fraction from $20 \%$ to $60 \%$ for a constant opening width of $100 \mu \mathrm{m}$, led to increasing photocurrent densities from $29.3 \pm 0.4 \mu \mathrm{A} \mathrm{cm}^{-2}$ to $39.4 \pm 0.8 \mu \mathrm{A}$ $\mathrm{cm}^{-2}$ for the soluble ruthenium mediator, and from $15.5 \pm 0.4$ to $31.1 \pm 0.6 \mu \mathrm{A} \mathrm{cm}{ }^{-2}$ for the osmium redox polymer mediator. When using an open area fraction of $0 \%$ (full C), no photocurrent was recorded, which is explained by the lack of light activation in the TMs, because the pyrolytic carbon is not transparent to light in the UV-visible range. In the case of the full opening, the entire surface area is exposed to light, but the absence of carbon in the measurement area should theoretically lead to no recording of photocurrent. However, low photocurrent values were recorded with the full opening: $1.8 \pm 0.2 \mu \mathrm{A} \mathrm{cm}{ }^{-2}$ for the ruthenium complex mediator, and $1.6 \pm 0.3 \mu \mathrm{A} \mathrm{cm}^{-2}$ for the osmium redox polymer. Since the opening is surrounded by carbon, the low photocurrent recorded is likely due to reactions taking place at the edges of the opening, in the vicinity of the surrounding electrode surface.

2.2.2. Influence of the distance between the photosynthetic reaction centers and the electrode surface on photocurrent generation

In Figure 2c, 2d, 3 and Table S1, it can be seen that for a constant open area fraction of $40 \%$, varying the width of the openings has a remarkable influence on the generated photocurrent. 
When decreasing the width of the openings from $400 \mu \mathrm{m}$ to $20 \mu \mathrm{m}$, the current density increased by a factor of two, from $23.1 \pm 0.4 \mu \mathrm{A} \mathrm{cm}{ }^{-2}$ to $53.2 \pm 0.8 \mu \mathrm{A} \mathrm{cm} \mathrm{cm}^{-2}$, for the soluble ruthenium mediator and by a factor of four, from $11.6 \pm 1 \mu \mathrm{A} \mathrm{cm}^{-2}$ to $42.8 \pm 0.6 \mu \mathrm{A} \mathrm{cm}^{-2}$, for the osmium redox polymer.

Regardless of the electrode pattern, the measured photocurrent values are higher when using soluble mediator, as opposed to polymeric mediator. This can be most likely attributed to the fact that the $\left[\mathrm{Ru}\left(\mathrm{NH}_{3}\right)_{6}\right]^{3+}$ ions can more easily access the PRCs, as discussed in Section 2.1.1. Additionally, the maximum photocurrent intensity is recorded after $5 \mathrm{~s}$ with the soluble mediator, and after $25 \mathrm{~s}$ with the osmium redox polymer, indicating that the electron transfer is slower in the latter case.

The experimental results show that the size of the openings has a major effect on the measured photocurrent. This can be attributed to the diffusion-based mechanism through which the charge is transported in the system by the two mediators. In order to understand the influence of the distance between the PRCs and the electrodes on photocurrent generation, a theoretical diffusion model described in the Experimental section and in the SI was employed ${ }^{52,53}$. The diffusion model assumes that the TMs are uniformly distributed on the surface area of the openings, which implies that electrons are generated with the same probability in all the points on the surface of the opening. In order to reach the electrode surface, electrons are transported in the system by the mediators in a manner approximated by isotropic two-dimensional diffusion. When a mediator in its reduced form reaches the electrode surface, an electron is transferred to the electrode and the mediator is re-oxidized, leading to photocurrent collection. The probability for an electron transported by a mediator to reach the electrode after a certain time interval is denoted as "exit 
probability". The sum of all exit probabilities of the electrons generated on the surface of the opening is considered to be proportional to the current intensity peak.

Figure 4a shows the theoretically calculated and experimentally obtained maximum current densities for electrode chips with an open area fraction of $40 \%$ as a function of the width of the openings. The theoretical model is in excellent agreement with the experimental data for both mediators. Figure $4 \mathbf{b}$ shows the exit probability as a function of the initial position of the electron for openings of increasing size after a time interval that corresponds to the maximum current intensities recorded for the two mediators using amperometry $(5 \mathrm{~s}$ for the soluble ruthenium mediator and $25 \mathrm{~s}$ for the osmium redox polymer mediator). The color-maps clearly indicate that the probability for electrons generated near the edge of the opening to reach the electrode surface within the time interval is higher. As the distance between a PRC and the electrode increases, the exit probability for a generated electron after the time interval corresponding to the maximum recorded photocurrent decreases (SI Figure S7). For distances above $35 \mu \mathrm{m}$, the exit probability is significantly lower than 1, meaning that an electron generated in the center of a large opening will not contribute to photocurrent collection. As it can be seen in Figure 4b, the exit probability is approximately 1 for the entire surface of the $20 \mu \mathrm{m}$ openings. Based on the experimental results and the model, the distance between individual PRCs and the electrode should be $10 \mu \mathrm{m}$ or lower for maximum photocurrent collection, where more or less all electrons generated by TMs are collected by the electrodes in the described setup 
The fit of the experimental current intensities to the theoretical model yields estimates of the effective two-dimensional diffusion coefficients, D. For the ruthenium complex, $\mathrm{D}_{\mathrm{Ru}}=17 \pm 3 \mu \mathrm{m}^{2}$ $\mathrm{s}^{-1}$, which is 30 times lower than the reported diffusion coefficient of $\left[\mathrm{Ru}\left(\mathrm{NH}_{3}\right)_{6}\right]^{3+}$ in $0.1 \mathrm{M}$ phosphate buffer at pH $7.0\left(\mathrm{D}=548 \mu \mathrm{m}^{2} \mathrm{~s}^{-1}\right)^{54}$. The large discrepancy can be ascribed to the high viscosity of the TM dispersion compared to the buffer solution, as well as to the fact that the $2 \mathrm{D}$

a

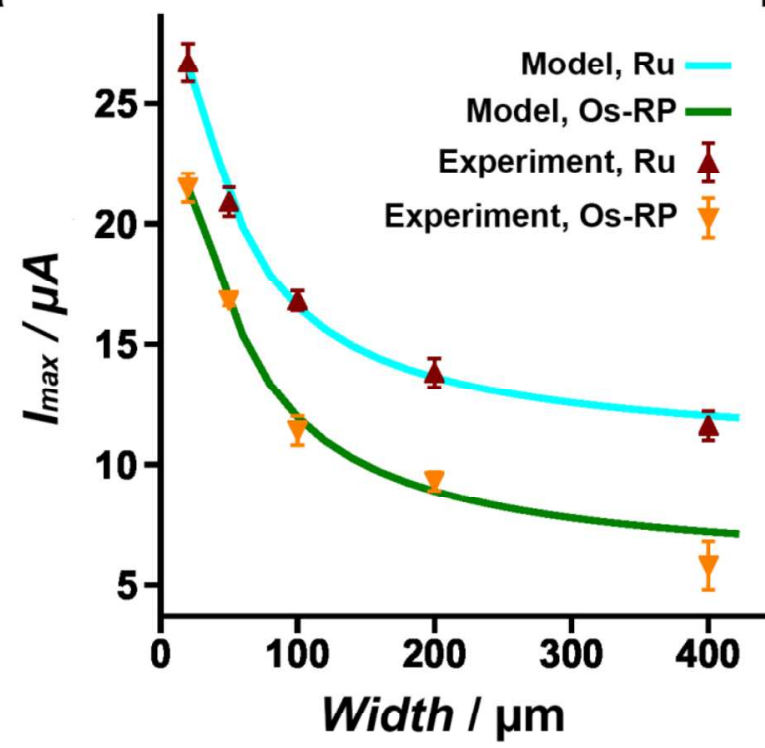

b
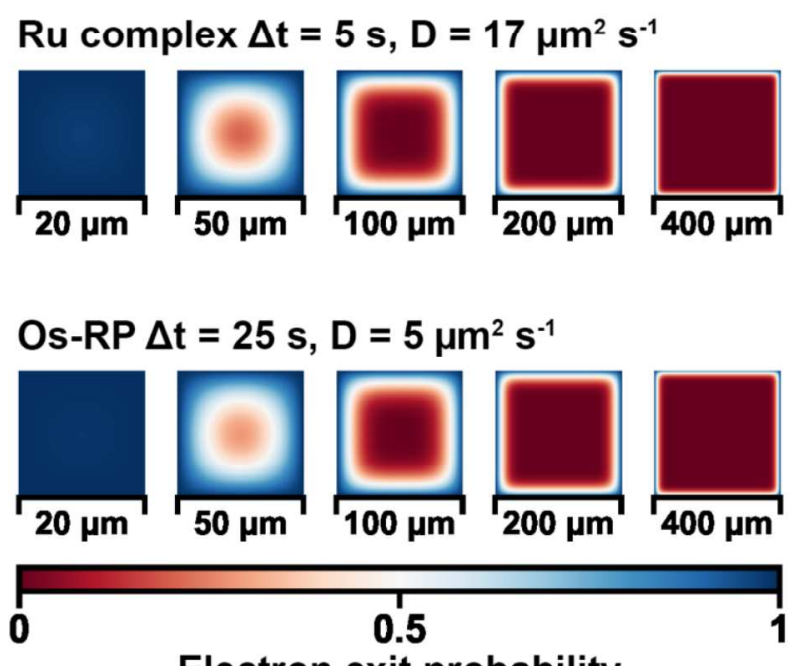

Figure 4: (a) Experimental maximum currents measured with electrode chips with a constant open area fraction of $40 \%$ and opening widths between 20 and $400 \mu \mathrm{m}\left(\boldsymbol{\Delta}\right.$-using $\left[\mathrm{Ru}\left(\mathrm{NH}_{3}\right)_{6}\right]^{3+}$ as mediator and $\boldsymbol{\nabla}$ using osmium redox polymer, Os-RP, as mediator) and corresponding curves obtained from the diffusion model. (b) Probability distribution on the surface of an opening for an electron generated in a certain position to reach the carbon electrode at a time point corresponding to the maximum measured current. The diffusion coefficients used to generate the color maps were calculated using the diffusion model.

model neglects out-of-plane displacement.

The electron transport through the osmium redox polymer occurs by an electron-hopping mechanism and can also be approximated as a diffusive process ${ }^{49,55}$. The effective in-plane diffusion coefficient was calculated to be $D_{\mathrm{Os}}=4 \pm 1 \mu \mathrm{m}^{2} \mathrm{~s}^{-1}$, which is in good agreement with experimental values reported in literature ${ }^{49}$.

2.2.3. Photocurrent generation in different illumination conditions 
Since only the openings in the carbon layer allow light to pass through the electrode chips and reach the TMs, it is expected that not all the thylakoids present on the electrode surface contribute to photocurrent generation when using back-side illumination. To investigate this, chips with $20 \mu \mathrm{m}$ openings and an open area fraction of $40 \%$ were tested using both back-side and top-side illumination with $1 \mathrm{mM}\left[\mathrm{Ru}\left(\mathrm{NH}_{3}\right)_{6}\right]^{3+}$ as mediator. The $20 \mu \mathrm{m}$ opening width was chosen since, as discussed in the previous section and shown in Figure 4b, the entire surface area of the openings contributes to photocurrent generation. For the top-side illumination, the light source was positioned to illuminate the top of the chip and all the other parameters were unaltered. Since the open area fraction for the tested chips was $40 \%$, top-side illumination leads to a 2.5 times increase in the surface area exposed to light, as compared to back-side illumination. However, the maximum current measured in top-side illumination mode was 45.2 $\pm 0.5 \mu \mathrm{A}$, which is only 1.7 times higher than in back-side illumination mode. One possible explanation is that, in the case of top-side illumination, the thylakoid moieties, which receive the most light, are positioned at the top of the TM layer, and the soluble mediator carrying the generated electrons can escape into the electrolyte solution instead of diffusing through the TM layer towards the electrode. Moreover, the TM layer attenuates the light, so it is expected that the thylakoids in close proximity to the carbon surface thus receive light with an intensity below 500 $\mathrm{W} \mathrm{m}{ }^{-2}$. Correspondingly, one of the advantages of the back-side illumination mode is that the light first reaches the lowermost part of the TM layer. This means that the electrons generated in the photosynthetic process reduce the mediator entities, which are already diffusing in the TM layer. Thus, the electrons are more likely to reach the electrode surface and lead to photocurrent generation, instead of diffusing into the electrolyte solution. 


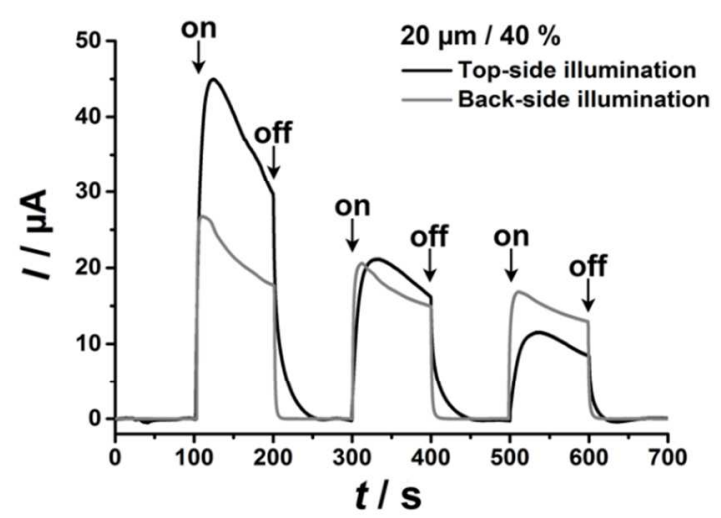

Figure 5: Comparison between photocurrent measured using back-side and top-side illumination for $20 \mu \mathrm{m} /$ $40 \%$ electrode chips with $1 \mathrm{mM}\left[\mathrm{Ru}\left(\mathrm{NH}_{3}\right)_{6}\right]^{3+}$ in PBS as mediator. $\mathrm{E}=0 \mathrm{~V}$ vs. $\mathrm{Ag} \mid \mathrm{AgCl}_{\text {sat. }}$. The light source was turned on and off every $100 \mathrm{~s}$ after the first $100 \mathrm{~s}$, as indicated by the arrows.
As shown in Figure 5, the photocurrent decrease in the top-side illumination mode is higher than in the back-side illumination mode. After the first $200 \mathrm{~s}$ of exposure to light, the photocurrent measured in back-side illumination mode is higher than in top-side illumination mode. This indicates that backside illumination might reduce light-induced damage in PS II.

For real-world applications in the energy sector, it is important to know how the electrode chips behave in different irradiance conditions. The value at which solar cells are tested is of $1000 \mathrm{~W} \mathrm{~m} \mathrm{~m}^{-2}$, which is also denoted as $1 \operatorname{sun}^{56}$. This value corresponds to normal illumination (when the sun is at zenith and its rays fall perpendicular to the ground). However, effective daytime irradiance has lower values, due to geometrical factors, terrain and atmospheric attenuation $^{57}$. Figure 6 shows amperograms (Figure 6a) and the maximum photocurrent density (Figure 6b) generated with the electrode chips with $20 \mu \mathrm{m}$ openings, an open area fraction of $40 \%$ and soluble mediator for different irradiance values, using back-side illumination. As seen in Figure 6a, for the tested interval of $200-1000 \mathrm{~W} \mathrm{~m}^{-2}$ higher irradiance values lead to higher currents, but also to a faster decrease in the photocurrent measured throughout the experiment. The latter is most likely a consequence of light-induced damage in PS II. The current density measured for an irradiance of 1 sun was $71 \mu \mathrm{A} \mathrm{cm} \mathrm{cm}^{-2}$. 
a

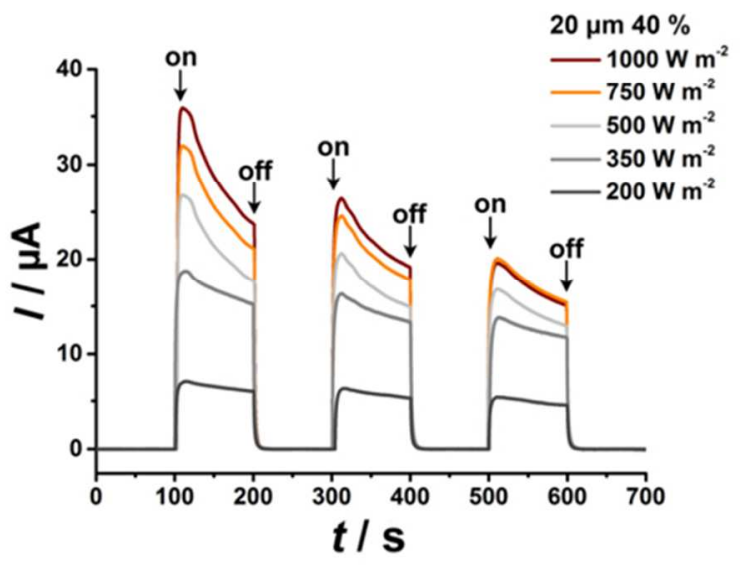

b

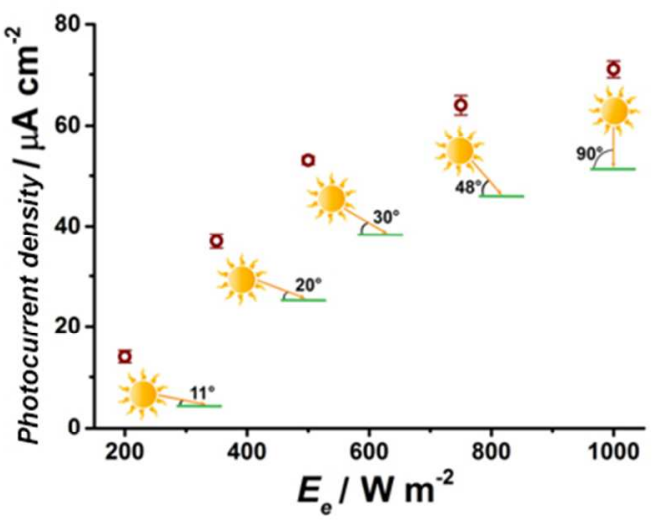

Figure 6: (a) Current-time trace for photocurrent collection from TMs for different irradiance values when using $20 \mu \mathrm{m} / 40 \%$ electrode chips with $1 \mathrm{mM}\left[\mathrm{Ru}\left(\mathrm{NH}_{3}\right)_{6}\right]^{3+}$ in $\mathrm{PBS}$ as mediator at $\mathrm{E}=0 \mathrm{~V}$ vs. $\mathrm{Ag} \mid \mathrm{AgCl}$ sat; $(\mathrm{b})$ Corresponding maximum current density as a function of irradiance. Sun drawings show the corresponding incident angle of solar light on a clear day for the irradiance values.

\subsection{Comparison to state-of-the-art}

In general, the photocurrent densities recorded in this work (see Table S1) for both $\left[\mathrm{Ru}\left(\mathrm{NH}_{3}\right)_{6}\right]^{3+}$ and osmium redox polymer using back-side illumination are higher than values previously reported on graphite electrodes using top-side illumination (between 24.9 and 51.7 $\mu \mathrm{A} \mathrm{cm}^{-2}$ using different mediators and an irradiance of $\left.6800 \mathrm{~W} \mathrm{~m}^{-2}\right)^{29}$. For a pattern with $20 \mu \mathrm{m}$ openings and an open area fraction of $40 \%$, the photocurrent density achieved using back-side illumination and soluble mediator $\left(71 \pm 0.6 \mu \mathrm{A} \mathrm{cm} \mathrm{cm}^{-2}\right.$ for an irradiance of $\left.1000 \mathrm{~W} \mathrm{~m}^{-2}\right)$ is similar to values previously reported on thylakoid-carbon nanotube composites in top-side illumination (68 $\mu \mathrm{A} \mathrm{cm}^{-2}$ for an irradiance of $\left.800 \mathrm{~W} \mathrm{~m}^{-2}\right)^{58}$. Higher photocurrent density values have previously been reported in top-side illumination mode by i) Hasan et al., for gold electrodes and parabenzoquinone as mediator (up to $130 \mu \mathrm{A} \mathrm{cm}^{-2}$ ); however, the light power of $6800 \mathrm{~W} \mathrm{~m}^{-2}$ was much higher than the one used in this work; ii) Pinhassi et al., for FTO electrodes employed in contact with a suspension of thylakoids (up to $500 \mu \mathrm{A} \mathrm{cm}^{-2}$ ). In this case, the chlorophyll content of the system was $0.1 \mathrm{mg}$ of chlorophyll, which is one order of magnitude higher than the chlorophyll content employed in this work (11.5 $\mu \mathrm{g}$ of chlorophyll). 
The quantum efficiency of the photosynthetic process for the $20 \mu \mathrm{m} / 40 \%$ chips was $0.64 \%$ for the $\left[\mathrm{Ru}\left(\mathrm{NH}_{3}\right)_{6}\right]^{3+}$ as mediator and $0.52 \%$ for the osmium redox polymer as mediator. This is in good agreement with previously reported quantum efficiency values ${ }^{14}$, which are in the range 0.3 to $3.3 \%$.

\section{Experimental section}

\subsection{Fabrication of electrode chips}

The electrode chips were fabricated using UV photolithography and pyrolysis. $500 \mu \mathrm{m}$ thick quartz wafers were employed as substrate and SU-8 2005 was used as carbon precursor. The process flow was as follows: overnight dehydration bake of the wafers at $250{ }^{\circ} \mathrm{C}$, spin coating of SU-8 2005: $30 \mathrm{~s}$, acceleration of $2000 \mathrm{rpm} \mathrm{min}^{-1}$ (RCD8 $\mathrm{T}$ spinner from Süss MicroTec, Germany), $3 \mathrm{~h}$ solvent evaporation at room temperature, proximity exposure, $12 \mu \mathrm{m}$ gap, through chromium mask and a dose of $100 \mathrm{~mJ} \mathrm{~cm}^{-1}$ (MA6 contact aligner from Süss MicroTec, Germany), $1 \mathrm{~h}$ bake at $50^{\circ} \mathrm{C}$, development: PGMEA, $2 \times 5 \mathrm{~min}$, followed by isopropanol washing and $\mathrm{N}_{2}$ blow-drying, $16 \mathrm{~h}$ hard bake at $90^{\circ} \mathrm{C}$, pyrolysis (PEO-601 furnace from ATV Technologie GmbH, Germany). The pyrolysis process was performed as previously reported ${ }^{59}$. The resist thickness was $5.9 \pm 0.2 \mu \mathrm{m}$ before pyrolysis and the obtained carbon layer had a thickness of $790 \pm 30 \mathrm{~nm}$, as measured with a DektakXT Stylus profilometer (Bruker, Billerica, MA, USA). A dicing saw (DAD 321 DISCO automatic, Japan) was used to dice the wafers. Each electrode chip has a footprint of $22 \times 22 \mathrm{~mm}$ and a patterned area of $10 \times 10 \mathrm{~mm}$ with the same positioning on all the different chip designs. In the patterned area, square openings permeating the carbon layer were designed in order to expose the transparent substrate material (Figure 1c and 1d) and thus to allow light to reach the TMs. Nine different chip designs were fabricated and tested. All chips were oxygen-plasma treated for 3 min using a power of $50 \mathrm{~W}$ with a $13.56 \mathrm{MHz}$ 
RF generator-equipped Atto Plasma System (Diener Electronic, GmbH, Ebhausen, Germany) before performing the electrochemical measurements.

\subsection{Photosynthetic process}

The thylakoid membranes (TMs) were extracted from Spinacia oleracea as described elsewhere $^{60}$. The chlorophyll content of the extracts was measured in accordance with literature ${ }^{61}$. The TM solution had a chlorophyll content of $3.2 \mathrm{mg} \mathrm{mL}^{-1}$ and it was preserved as deep-frozen aliquots $\left(-80^{\circ} \mathrm{C}\right)$ and thawed before performing the experiments.

A 150W 220 V fiber optic illuminator (Titan Tool Supply, Inc. Buffalo, NY, USA) providing white visible light was used to induce photosynthesis in the TMs. The irradiance was calibrated using a light intensity meter (Techtum Lab AB, Umeå, Sweden) and adjusted to $500 \mathrm{~W} \mathrm{~m}^{-2}$ unless otherwise specified. The TMs were illuminated through the transparent electrode chips (back-side illumination) for all experiments unless otherwise specified. The correlation between the open area fraction and irradiance measured through the chips is shown in Figure S4.

The quantum efficiency of the system represents the ratio between the number of electrons generated and the number of photons absorbed by the sample, in percentage form. We calculated the apparent quantum efficiency of our system for the $20 \mu \mathrm{m} / 40 \%$ chips, as this is the only electrode pattern in which all the generated electrons are shown to be harvested in the system (Figure 4). The number of electrons was calculated from experimental current data points. The number of photons that the sample was exposed to was calculated from the irradiance value measured through the $20 \mu \mathrm{m} / 40 \%$ chips, considering an average photosynthetic response wavelength of $520 \mathrm{~nm}$. The calculation assumes that all the photons that pass through the electrode chip are absorbed by the sample.

\subsection{Electrochemical measurements}


$\mathrm{MgCl}_{2}$ was purchased from Scharlau Chemie S.A. $\mathrm{NaCl} \quad(433209, \geq 99 \%$, Hexaammineruthenium (II) chloride (303690, $\geq 99.9 \%$ ) and hexaammineruthenium (III) chloride $(262005, \geq 98 \%)$ were purchased from Sigma Aldrich. [Os(2,2'-bipyridine) $)_{2}$-poly(Nvinylimidazole $\left.)_{10} \mathrm{Cl}\right]^{+/ 2+}$ was synthesized as previously reported ${ }^{62}$. Millipore water (18.2 $\mathrm{M} \Omega$ resistivity) was used for preparing all solutions.

Cyclic voltammetry (CV) and amperometry (A) measurements were performed using a PalmSens potentiostat (EmStat2, Utrecht, The Netherlands) and the PSTrace software in a conventional three-electrode setup. DRIREF-L, a $\mathrm{Ag} \mid \mathrm{AgCl}_{\text {sat }}$ electrode from WPI (UK) was employed as reference electrode (RE). A Pt wire $(500 \mu \mathrm{m}$ diameter, from Advent Research Materials, UK) was used as counter electrode (CE). The different electrode chips were interfaced to the potentiostat using copper wires and used as working electrodes (WEs) in a setup designed for these experiments and described in the SI. The measurement chamber defines the active electrode footprint area to be $0.5 \mathrm{~cm}^{2}$. The electrolyte is $10 \mathrm{mM}$ phosphate buffer with $10 \mathrm{mM}$ $\mathrm{NaCl}$ and $5 \mathrm{mM} \mathrm{MgCl}$ (PBS). The electrolyte solution was degassed by purging with nitrogen for at least $10 \mathrm{~min}$ before experiments. $1 \mathrm{mM}\left[\mathrm{Ru}\left(\mathrm{NH}_{3}\right)_{6}\right] \mathrm{Cl}_{2} /\left[\mathrm{Ru}\left(\mathrm{NH}_{3}\right)_{6}\right] \mathrm{Cl}_{3}$ in $\mathrm{PBS}$ was used to characterize the electrode behavior (SI, Figure S2 and S3).

For experiments with TMs and soluble mediator, $3.6 \mu \mathrm{L}$ of TM extract (optimized value, corresponding to $11.5 \mu \mathrm{g}$ of chlorophyll) was first dropcast on the patterned area of the electrode chip $\left(11.5 \mu \mathrm{g} \mathrm{cm}^{-2}\right)$. After $5 \mathrm{~min}$, a dialysis membrane (Spectrum Laboratories Inc., USA, MWCO: 6-8 $\mathrm{kDa}$ ) presoaked in buffer was added and the chip was immediately assembled in the designed holder. A was then performed at $0.0 \mathrm{~V}$ vs $\mathrm{Ag} \mid \mathrm{AgCl}_{\text {sat }}$ in $1 \mathrm{mM}\left[\mathrm{Ru}\left(\mathrm{NH}_{3}\right)_{6}\right] \mathrm{Cl}_{3}$ in $\mathrm{PBS}$, a more positive potential than the $\mathrm{E}^{\circ}$ of the couple, which is $-0.1 \mathrm{~V}$ vs. $\mathrm{Ag} \mid \mathrm{AgCl} \mathrm{sat}_{\text {sa }}$. 
For experiments with TMs and osmium-redox-polymer (Os-RP) as mediator, a solution of 10 $\mathrm{mg} \mathrm{mL} \mathrm{m}^{-1}\left[\mathrm{Os}\left(2,2^{\prime} \text {-bipyridine }\right)_{2} \text {-poly }(\mathrm{N} \text {-vinylimidazole }){ }_{10} \mathrm{Cl}\right]^{+/ 2+}$ (redox potential $+0.22 \mathrm{~V}$ vs. $\left.\mathrm{Ag} \mid \mathrm{AgCl}_{\text {sat }}\right)$ in milli-Q water was first prepared. $15 \mu \mathrm{L}$ of Os-RP solution was deposited onto the patterned area and allowed to dry at room temperature for $1 \mathrm{~h}$ (optimized values for volume and drying time). After that, TMs and dialysis membrane were added in the same way as for experiments with soluble mediator. A was then performed at $+0.22 \mathrm{~V}$ vs. $\mathrm{Ag} \mid \mathrm{AgCl}$ sat in electrolyte solution.

All data presented is based on three independent experiments and the standard deviation is less than $10 \%$. Baseline correction was used for all amperometric measurements, as described in the SI and shown in Figure S5. Control experiments without TMs (SI, Figure S6) were used to ensure the currents reported in this paper are due to the photosynthetic process. Maximum current densities are calculated by using the current measured $5 \mathrm{~s}$ after the first illumination pulse when using $\left[\mathrm{Ru}\left(\mathrm{NH}_{3}\right)_{6}\right]^{3+}$ as mediator or $25 \mathrm{~s}$ after the first illumination pulse when using Os redox polymer as mediator.

\subsection{Theoretical diffusion model and calculations}

Electrons are generated through photosynthetic reactions on the square surfaces representing the openings in the carbon layer. Thus, at the start of the illumination pulse, the electrons are considered to be uniformly distributed on the openings in the carbon layer.

Electrons transported by the mediators were modeled as non-interacting particles freely diffusing in two dimensions. The probability for an electron to escape the irradiated region where it is generated, during an interval of time, was calculated.

An electron is transferred to the electrode as soon as the mediator transports it to the carbon surface, meaning that it diffuses outside the irradiated region. The current intensity is hence 
related to the average probability for an electron to reach the boundary during the time interval between the illumination pulse and the measurement of the current intensity peak.

As detailed in the SI (Section S6), the time-dependent exit probability of a particle in a square surface with absorbing boundaries was used ${ }^{53,63}$, and this parameter was averaged over all starting positions on the square. The average electron exit probability is a function of the width of the opening, the time interval, and the effective diffusion coefficient of the mediator transporting the electron. Experimental current intensities were fitted to the average electron exit probability.

\section{Conclusions}

Patterning a conductive material on a transparent substrate is advantageous for both lightinduced energy conversion and for efficient energy collection. Carbon-on-quartz transparent electrode chips were fabricated and successfully employed for photocurrent generation from TMs using back-side illumination with solar-simulated irradiance. Square openings in the carbon layer defined the regions of the samples that were exposed to light.

Two design parameters of the micropatterned electrodes were shown to influence photocurrent generation. An increase in the open area fraction up to $60 \%$ led to an enhanced photocurrent generation. Increasing the open area fraction further was not feasible in the current system, since it would result in a width of the carbon electrodes smaller than $5 \mu \mathrm{m}$, which becomes a challenge for patterning with standard UV photolithography. In the future, larger open area fractions could be achieved with different fabrication methods of the electrode patterns. The second parameter that had a high impact on photocurrent generation was the width of the openings in the carbon layer, which influences the distances between the photosynthetic reaction centers and the electrode. Openings larger than $20 \mu \mathrm{m}$ require charge transfer over a large distance between the 
TM PRC and the electrode, leading to a decrease in the recorded photocurrent. This was explained by a diffusion model where electrons transported by the mediators were modeled as non-interacting particles freely propagating in two dimensions. The model showed that in order to maximize photocurrent collection, the distance between the photosynthetic reaction centers and the electrode surface should be below $10 \mu \mathrm{m}$, which corresponds to an opening width of 20 $\mu \mathrm{m}$.

The patterned electrode chips presented in this work can be fabricated in a scalable process and allow photocurrent generation from TMs with competitive results, for relevant irradiance values. In addition, they allow minimizing the necessary reagent consumption (low chlorophyll content required) and protecting the system from the environment and vice-versa by using back-side illumination, which can be employed in the future for building closed PBECs. An additional increase in electrode surface area could eventually be achieved by patterning three-dimensional polymer structures before pyrolysis ${ }^{42-44}$ which in principle could lead to enhanced photocurrent generation.

ASSOCIATED CONTENT

\title{
Supporting Information.
}

The following files are available free of charge.

Additional experimental details and results (PDF)

Jupyter Notebook for calculations (native and HTML format)

\author{
AUTHOR INFORMATION
}

Corresponding Authors 
Ada-Ioana Bunea, PhD: adabu@fotonik.dtu.dk; Technical University of Denmark, Department of Photonics Engineering, Bld. 343, Ørsteds Plads, Kgs. Lyngby, 2800, DK.

Jenny Emnéus, Professor: jenny.emneus@nanotech.dtu.dk; Technical University of Denmark, Department of Micro and Nanotechnology, Bld. 345C, Ørsteds Plads, Kgs. Lyngby, 2800, DK.

Present Addresses

$\$$ Department of Photonics Engineering, Technical University of Denmark, 2800 Kongens Lyngby, Denmark.

\title{
Author Contributions
}

The manuscript was written through contributions of all authors. All authors have given approval to the final version of the manuscript.

\section{Funding Sources}

S. S. K. acknowledges funding by the Young Investigator Program of the Villum Foundation, project no. VKR023438.

\section{ACKNOWLEDGMENT}

Nanna Bild and Jesper Scheel from DTU Nanotech are acknowledged for their help with graphic design and photography.

\author{
ABBREVIATIONS \\ TM - thylakoid membrane \\ PBEC - Photo-bioelectrochemical cell \\ PS I - Photosystem I \\ PS II - Photosystem II \\ TCO - Transparent conductive oxides
}


FTO - Fluorinated tin oxide

ITO - Indium tin oxide

PRC - Photosynthetic reaction center

SI - Supporting information

\section{REFERENCES}

(1) Bohi, D. R.; Zimmerman, M. B. An Update on Econometric Studies of Energy Demand Behavior. Annu. Rev. Energy 1984, 9, 105-154.

(2) Haas, R.; Auer, H.; Biermayr, P. The Impact of Consumer Behavior on Residential Energy Demand for Space Heating. Energy Build. 1998, 27, 195-205.

(3) Isaac, M.; van Vuuren, D. P. Modeling Global Residential Sector Energy Demand for Heating and Air Conditioning in the Context of Climate Change. Energy Policy 2009, 37, $507-521$.

(4) Dincer, I. Renewable Energy and Sustainable Development: A Crucial Review. Renew. Sustain. Energy Rev. 2000, 4, 157-175.

(5) Bilgen, S.; Kaygusuz, K.; Sari, A. Renewable Energy for a Clean and Sustainable Future. Energy Sources 2004, 26, 1119-1129.

(6) Panwar, N. L.; Kaushik, S. C.; Kothari, S. Role of Renewable Energy Sources in Environmental Protection: A Review. Renew. Sustain. Energy Rev. 2011, 15, 1513-1524.

(7) Hedley, G. J.; Ruseckas, A.; Samuel, I. D. W. Light Harvesting for Organic Photovoltaics. Chem. Rev. 2017, 117, 796-837.

(8) Burschka, J.; Pellet, N.; Moon, S.-J.; Humphry-Baker, R.; Gao, P.; Nazeeruddin, M. K.; Grätzel, M. Sequential Deposition as a Route to High-Performance Perovskite-Sensitized Solar Cells. Nature 2013, 499, 316-319. 
(9) Kundu, S.; Patra, A. Nanoscale Strategies for Light Harvesting. Chem. Rev. 2017, 117, $712-757$.

(10) Grätzel, M. Recent Advances in Sensitized Mesoscopic Solar Cells. Acc. Chem. Res. 2009, 42, 1788-1798.

(11) Albertsson, P.-A. The Structure and Function of the Chloroplast Photosynthetic Membrane -a Model for the Domain Organization. Photosynth. Res. 1995, 46, 141-149.

(12) Chen, M.-Y.; Zhuo, G.-Y.; Chen, K.-C.; Wu, P.-C.; Hsieh, T.-Y.; Liu, T.-M.; Chu, S.-W. Multiphoton Imaging to Identify Grana, Stroma Thylakoid, and Starch inside an Intact Leaf. BMC Plant Biol. 2014, 175, 113704.

(13) Tel-Vered, R.; Willner, I. Photo-Bioelectrochemical Cells for Energy Conversion, Sensing, and Optoelectronic Applications. ChemElectroChem 2014, 1, 1778-1797.

(14) Yehezkeli, O.; Tel-Vered, R.; Wasserman, J.; Trifonov, A.; Michaeli, D.; Nechushtai, R.; Willner, I. Integrated Photosystem II-Based Photo-Bioelectrochemical Cells. Nat. Commun. 2012, 3, 742.

(15) Efrati, A.; Lu, C.-H.; Michaeli, D.; Nechushtai, R.; Alsaoub, S.; Schuhmann, W.; Willner, I. Assembly of Photo-Bioelectrochemical Cells Using Photosystem I-Functionalized Electrodes. Nat. Energy 2016, 1, 15021.

(16) Yehezkeli, O.; Tel-Vered, R.; Michaeli, D.; Willner, I.; Nechushtai, R. Photosynthetic Reaction Center-Functionalized Electrodes for Photo-Bioelectrochemical Cells. Photosynth. Res. 2014, 120, 71-85.

(17) Pankratova, G.; Pankratov, D.; Hasan, K.; Åkerlund, H.-E.; Albertsson, P.-Å.; Leech, D.; Shleev, S.; Gorton, L. Supercapacitive Photo-Bioanodes and Biosolar Cells: A Novel Approach for Solar Energy Harnessing. Adv. Energy Mater. 2017, 1602285. 
(18) Pankratov, D.; Pankratova, G.; Dyachkova, T. P.; Falkman, P.; Åkerlund, H.-E.; Toscano, M. D.; Chi, Q.; Gorton, L. Supercapacitive Biosolar Cell Driven by Direct Electron Transfer between Photosynthetic Membranes and CNT Networks with Enhanced Performance. ACS Energy Lett. 2017, 2, 2635-2639.

(19) Pankratova, G.; Pankratov, D.; Di Bari, C.; Goñi-Urtiaga, A.; Toscano, M. D.; Chi, Q.; Pita, M.; Gorton, L.; De Lacey, A. L. Three-Dimensional Graphene Matrix-Supported and Thylakoid Membrane-Based High-Performance Bioelectrochemical Solar Cell. ACS Appl. Energy Mater. 2018, 1, 319-323.

(20) Tsujimura, S.; Wadano, A.; Kano, K.; Ikeda, T. Photosynthetic Bioelectrochemical Cell Utilizing Cyanobacteria and Water-Generating Oxidase. Enzyme Microb. Technol. 2001, $29,225-231$.

(21) Hasan, K.; Reddy, K. V. R.; Eßmann, V.; Górecki, K.; Conghaile, P. O.; Schuhmann, W.; Leech, D.; Hägerhäll, C.; Gorton, L. Electrochemical Communication between Electrodes and Rhodobacter Capsulatus Grown in Different Metabolic Modes. Electroanalysis 2015, $27,118-127$.

(22) Wong, M. T.; Cheng, D.; Wang, R.; Hsing, I. M. Modifying the Endogenous Electron Fluxes of Rhodobacter Sphaeroides 2.4.1 for Improved Electricity Generation. Enzyme Microb. Technol. 2016, 86, 45-51.

(23) Xiao, L.; Young, E. B.; Berges, J. A.; He, Z. Integrated Photo-Bioelectrochemical System for Contaminants Removal and Bioenergy Production. Environ. Sci. Technol. 2012, 46, 11459-11466.

(24) Bombelli, P.; Zarrouati, M.; Thorne, R. J.; Schneider, K.; Rowden, S. J. L.; Ali, A.; Yunus, K.; Cameron, P. J.; Fisher, A. C.; Ian Wilson, D.; Howe, C. J.; McCormick, A, J. 
Surface Morphology and Surface Energy of Anode Materials Influence Power Outputs in a Multi-Channel Mediatorless Bio-Photovoltaic (BPV) System. Phys. Chem. Chem. Phys. 2012, 14, 12221.

(25) González-Arribas, E.; Aleksejeva, O.; Bobrowski, T.; Toscano, M. D.; Gorton, L.; Schuhmann, W.; Shleev, S. Solar Biosupercapacitor. Electrochem. commun. 2017, 74, 913.

(26) Lee, J.; Kim, S. Mediator-Free Solar Energy Conversion by the Artificially Installed Thylakoid Membrane on the Functionalized Electrode. Electrochem. commun. 2014, 49, $55-59$.

(27) Dewi, H. A.; Meng, F.; Sana, B.; Guo, C.; Norling, B.; Chen, X.; Lim, S. Investigation of Electron Transfer from Isolated Spinach Thylakoids to Indium Tin Oxide. RCS Adv. 2014, $4,48815-48820$.

(28) Hasan, K.; Dilgin, Y.; Emek, S. C.; Tavahodi, M.; Åkerlund, H.-E.; Albertsson, P.-Å.; Gorton, L. Photoelectrochemical Communication between Thylakoid Membranes and Gold Electrodes through Different Quinone Derivatives. ChemElectroChem 2014, 1, 131139.

(29) Hamidi, H.; Hasan, K.; Emek, S. C.; Dilgin, Y.; Åkerlund, H.-E.; Albertsson, P.-Å.; Leech, D.; Gorton, L. Photocurrent Generation from Thylakoid Membranes on OsmiumRedox-Polymer-Modified Electrodes. ChemSusChem 2015, 8, 990-993.

(30) McCormick, A. J.; Bombelli, P.; Bradley, R. W.; Thorne, R.; Wenzel, T.; Howe, C. J. Biophotovoltaics: Oxygenic Photosynthetic Organisms in the World of Bioelectrochemical Systems. Energy Environ. Sci. 2015, 8, 1092-1109.

(31) Fortunato, Elvira; Ginley, David; Hosono, Hideo; Paine, D. C. Transparent Conducting 
Oxides for Photovoltaics. MRS Bull. 2007, 32, 242-247.

(32) Ellmer, K. Past Achievements and Future Challenges in the Development of Optically Transparent Electrodes. Nat. Photonics 2012, 6, 809-817.

(33) Pinhassi, R. I.; Kallmann, D.; Saper, G.; Dotan, H.; Linkov, A.; Kay, A.; Liveanu, V.; Schuster, G.; Adir, N.; Rothschild, A. Hybrid Bio-Photo-Electro-Chemical Cells for Solar Water Splitting. Nat. Commun. 2016, 7, 12552.

(34) Kumar, A.; Zhou, C. The Race To Replace Tin-Doped Indium Oxide: Which Material Will Win? ACS Nano 2010, 4, 11-14.

(35) Pang, S.; Hernandez, Y.; Feng, X.; Müllen, K. Graphene as Transparent Electrode Material for Organic Electronics. Adv. Mater. 2011, 23, 2779-2795.

(36) Wu, H.; Kong, D.; Ruan, Z.; Hsu, P.-C.; Wang, S.; Yu, Z.; Carney, T. J.; Hu, L.; Fan, S.; Cui, Y. A Transparent Electrode Based on a Metal Nanotrough Network. Nat. Nanotechnol. 2013, 8, 421-425.

(37) Wang, X.; Zhi, L.; Mu, K. Transparent, Conductive Graphene Electrodes for DyeSensitized Solar Cells. Nano Lett. 2008, 8, 323-327.

(38) Wang, G.; Zhang, L.; Zhang, J. A Review of Electrode Materials for Electrochemical Supercapacitors. Chem. Soc. Rev. Chem. Soc. Rev 2012, 41, 797-828.

(39) Zhou, M.; Chi, M.; Luo, J.; He, H.; Jin, T. An Overview of Electrode Materials in Microbial Fuel Cells. J. Power Sources 2011, 196, 4427-4435.

(40) You, P. Y.; Kamarudin, S. K. Recent Progress of Carbonaceous Materials in Fuel Cell Applications: An Overview. Chem. Eng. J. 2017, 309, 489-502.

(41) McCreery, R. L. Advanced Carbon Electrode Materials for Molecular Electrochemistry. Chem. Rev. 2008, 108, 2646-2687. 
(42) Amato, L.; Heiskanen, A.; Hansen, R.; Gammelgaard, L.; Rindzevicius, T.; Tenje, M.; Emnéus, J.; Keller, S. S. Dense High-Aspect Ratio 3D Carbon Pillars on Interdigitated Microelectrode Arrays. Carbon 2015, 94, 792-803.

(43) Amato, L.; Keller, S. S.; Heiskanen, A.; Dimaki, M.; Emnéus, J.; Boisen, A.; Tenje, M. Fabrication of High-Aspect Ratio SU-8 Micropillar Arrays. Microelectron. Eng. 2012, 98, 483-487.

(44) Hemanth, S.; Caviglia, C.; Keller, S. S. Suspended 3D Pyrolytic Carbon Microelectrodes for Electrochemistry. Carbon 2017, 121, 226-234.

(45) Singh, A.; Jayaram, J.; Madou, M.; Akbar, S. Pyrolysis of Negative Photoresists to Fabricate Carbon Structures for Microelectromechanical Systems and Electrochemical Applications. J. Electrochem. Soc. 2002, 149, E78.

(46) Bansal, N. P.; Doremus, R. H. Handbook of Glass Properties; Academic Press, 1986.

(47) Yamada, S.; Sato, H. Some Physical Properties of Glassy Carbon. Nature 1962, 193, $261-$ 262.

(48) Pesin, L. A. Structure and Properties of Glass-like Carbon. J. Mater. Sci. 2002, 37, 1-28.

(49) Aoki, A.; Heller, A. Electron Diffusion Coefficients in Hydrogels Formed of CrossLinked Redox Polymers. J. Phys. Chem. 1993, 97, 11014-11019.

(50) Bard, A. J.; Faulkner, L. R. Electrochemical Methods : Fundamentals and Applications, 2nd ed.; Wiley, 2001.

(51) Melis. Photosystem-II Damage and Repair Cycle in Chloroplasts: What Modulates the Rate of Photodamage? Trends Plant Sci. 1999, 4, 130-135.

(52) Fick, A. Ueber Diffusion. Ann. der Phys. und Chemie 1855, 170, 59-86.

(53) Siegel, R. A.; Langert, R. A New Monte Carlo Approach to Diffusion in Constricted 
Porous Geometries. J. Colloid Interface Sci. 1986, 109, 426-440.

(54) Baur, J. E.; Wightman, R. M. Diffusion Coefficients Determined with Microelectrodes. $J$. Electroanal. Chem. Interfacial Electrochem. 1991, 305, 73-81.

(55) Pickup, P. G.; Murray, R. W. Redox Conduction in Mixed-Valent Polymers. J. Am. Chem. SOC. J. Phys. Chem. J. Electroanal. Chem 1983, 105, 4510-4514.

(56) Green, M. A.; Emery, K.; Hishikawa, Y.; Warta, W.; Dunlop, E. D. Solar Cell Efficiency Tables. Prog. Photovoltaics Res. Appl. 2015, 23, 1-9.

(57) Suri, M.; Hofierka, J. A New GIS-Based Solar Radiation Model and Its Application to Photovoltaic Assessments. Trans. GIS 2004, 8, 175-190.

(58) Calkins, J. O.; Umasankar, Y.; O’Neill, H.; Ramasamy, R. P. High Photo-Electrochemical Activity of Thylakoid-carbon Nanotube Composites for Photosynthetic Energy Conversion. Energy Environ. Sci. 2013, 6, 1891-1900.

(59) Amato, L.; Heiskanen, A.; Caviglia, C.; Shah, F.; Zór, K.; Skolimowski, M.; Madou, M.; Gammelgaard, L.; Hansen, R.; Seiz, E. G.; Ramos, M.; Ramos Moreno, T.; MartínezSerrano, A.; Keller, S. S.; Emnéus, J. Pyrolysed 3D-Carbon Scaffolds Induce Spontaneous Differentiation of Human Neural Stem Cells and Facilitate Real-Time Dopamine Detection. Adv. Funct. Mater. 2014, 24, 7042-7052.

(60) Andreasson, E.; Svensson, P.; Weibull, C.; Albertsson, P.-A. Separation and Characterization of Stroma and Grana Membranes - Evidence for Heterogeneity in Antenna Size of Both Photosystem I and Photosystem II. Biochim. Biophys. Acta Bioenerg. 1988, 936, 339-350.

(61) Porra, R. J.; Thompson, W. A.; Kriedemann, P. E. Determination of Accurate Extinction Coefficients and Simultaneous Equations for Assaying Chlorophylls a and B Extracted 
with Four Different Solvents: Verification of the Concentration of Chlorophyll Standards by Atomic Absorption Spectroscopy. Biochim. Biophys. Acta Modem Methods Plant Anal. 1989, 975, 384-394.

(62) Barrière, F.; Ferry, Y.; Rochefort, D.; Leech, D. Targetting Redox Polymers as Mediators for Laccase Oxygen Reduction in a Membrane-Less Biofuel Cell. Electrochem. commun. 2004, 6, 237-241.

(63) Redner, S. A Guide to First-Passage Processes; Cambridge University Press, 2001. 
Table of contents graphic:

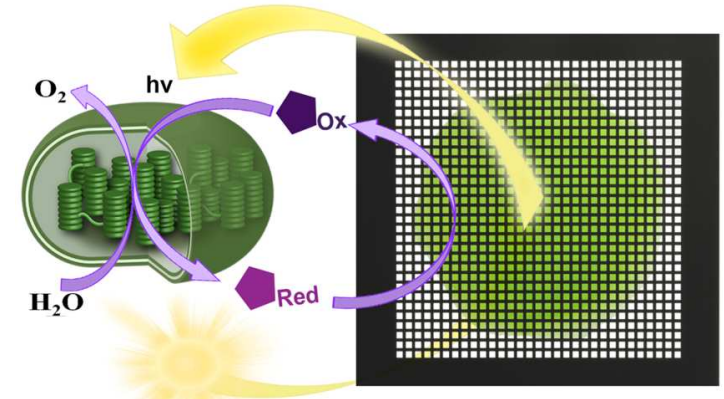

15

16

17

18

19

20

21

22

23

24

25

26

27

28

29

30

31

32

33

34

35

36

37

38
39

40

41

42

43

44

45

46

47

48

49

50

51

52

53

54

55

56

57

58

59

60

ACS Paragon Plus Environment 